\title{
Metabolic Profiling of the Hippocampus of Rats Experiencing Nicotine- Withdrawal Symptoms
}

\author{
Hayato Akimoto, ${ }^{a}$ Shinji Oshima, ${ }^{* a}$ Yuichi Michiyama, ${ }^{a}$ Akio Negishi, ${ }^{a}$ Tadashi Nemoto, ${ }^{b}$ and \\ Daisuke Kobayashi $^{a}$ \\ ${ }^{a}$ Faculty of Pharmacy and Pharmaceutical Sciences, Josai University; 1-1 Keyakidai, Sakado, Saitama 350-0295, \\ Japan: and ${ }^{b}$ Biomedical Research Institute, National Institute of Advanced Industrial Science and Technology (AIST); \\ 1-1 Higashi, Tsukuba, Ibaraki 305-8566, Japan. \\ Received June 26, 2018; accepted September 17, 2018; advance publication released online October 2, 2018
}

\begin{abstract}
Nicotine-withdrawal symptoms have been indicated as a possible risk factor for neuropsychiatric events, such as depression and suicide, during use of smoking-cessation drugs. We aimed to investigate whether the results of the metabolomic analysis of the rat brain reflect nicotine-withdrawal symptoms. We also aimed to investigate the relative changes in each metabolite in the brains of rats with nicotine-withdrawal symptoms. We created rats experiencing nicotine-withdrawal symptoms through repeat administration of nicotine followed by a 12-h withdrawal period, and rats recovered from nicotine-withdrawal symptoms followed by an 18-h withdrawal period. We then implemented brain metabolic profiling by combining high-resolution magic-angle spinning ${ }^{1} \mathrm{H}$-NMR spectroscopy with partial least square discriminant analysis (PLS-DA). We found that metabolic profiling of the brain reflects the state during nicotine-withdrawal symptoms and the state after recovery from nicotine-withdrawal symptoms. Additionally, $N$-acetylaspartate and glutamate increased and aspartate, $\gamma$-aminobutyric acid (GABA), and creatine decreased in the hippocampus of rats experiencing nicotine-withdrawal symptoms. Therefore, it is suggested that neurogenesis and neuronal differentiation could be changed and abnormal energy metabolism could occur in the hippocampus during nicotine-withdrawal symptoms.
\end{abstract}

Key words nicotine-withdrawal; metabolomics; hippocampus; NMR spectroscopy; $N$-acetylaspartate

At present, varenicline, bupropion, and nicotine preparations are used clinically as smoking-cessation drugs, but varenicline in particular is known as a drug with a high abstinence rate compared to other smoking-cessation drugs. ${ }^{1,2)}$ In contrast, in July 2009, the Food and Drug Administration (FDA) issued a boxed warning that "use of varenicline is related to changes in behaviour, including hostility, agitation, depressed mood, and suicidal thoughts or actions." ${ }^{3)}$

Based on data analysis using the FDA Adverse Event Reporting System, we reported that there is a high risk of depression and suicide-related events in cases that had used varenicline. ${ }^{4)}$ However, it was unclear whether the factors that increase the risk of depression and suicide-related events in those cases were due to the direct effect of varenicline or due to the smoking-cessation therapy itself. A report by Anthenelli et $a l^{3)}$ found no risk difference between smoking-cessation drugs and placebo in terms of neuropsychiatric events that developed during the period of smoking-cessation therapy using these drugs, so it is unlikely that the direct effect of these drugs is the principal factor. Additionally, in the same article, neuropsychiatric events were seen in the group administered placebo, so smoking cessation itself may be a risk factor. ${ }^{5-7)}$

Some studies have suggested that the hippocampus is associated with not only memory and cognitive function but also mood regulation. ${ }^{8-10)}$ In clinical studies, it is reported that memory and cognitive function are impaired by nicotine abstinence. $^{11-13)}$

In this study, we aimed to investigate whether the results of the metabolomic analysis of the rat hippocampus reflect nicotine-withdrawal symptoms. We also aimed to investigate the relative changes in each metabolite in the hippocampi of rats with nicotine-withdrawal symptoms.

\section{MATERIALS AND METHODS}

Animals Seven-week-old male Wistar/ST rats were purchased from Sankyo Labo Service Corporation, Inc. (Tokyo, Japan). Rats were housed at a controlled ambient temperature of $25 \pm 2{ }^{\circ} \mathrm{C}$ with $55 \pm 5 \%$ relative humidity and a 12 -h light/ dark cycle (lights on at 7:00a.m.). They were fed a normal chow diet and water was provided ad libitum. Experiments were initiated following a habituation period of at least 1 week.

All animal experiments were performed in accordance with the Guideline for Proper Conduct of Animal Experiments established by Science Council of Japan (Josai University approval number: H28022-2017/3/16).

Establishment of Nicotine-Withdrawal Rats We decided on the nicotine dose and withdrawal period based on the reports by Epping-Jordan et al. ${ }^{14-16)}$ To create a rat model of nicotine-withdrawal symptoms, Nicotine Bi-L-(+)-tartrate Dihydrate (Tokyo Chemical Industry Co., Ltd., Tokyo, Japan) was dissolved in saline solution and $0.75 \mathrm{mg} / \mathrm{kg}$ (as nicotine) was administered via subcutaneous injection four times a day $(10: 30,14: 00,17: 30$, and $21: 00)$ for $14 \mathrm{~d}$ to the rats, and the withdrawal period was set as 12 and $18 \mathrm{~h}$ from the final nicotine subcutaneous administration (Nic_12 and Nic_18 groups; $n=6 /$ group). Saline solution was administered subcutaneously on the same schedule to the control rats, and the withdrawal period was set as $12 \mathrm{~h}$ and $18 \mathrm{~h}$ (Sal_12 and Sal_18 groups; $n=6$ /group).

Behavioural Pharmacological Testing We implemented 
an open field test (OFT) to confirm that the Nic 12 and Nic_18 groups were experiencing nicotine-withdrawal symptoms. The OFT was implemented in a room with a quiet environment $(<60 \mathrm{~dB})$, in accordance with previous studies. $\left.{ }^{17}\right)$ We used a plastic apparatus in which the pearl grey floor $(100 \times 100 \mathrm{~cm})$ was divided into 25 squares by grey lines. Each rat was gently placed at the centre of the apparatus and the behaviour was video-recorded for $6 \mathrm{~min}$. The occurrences of grid line crossings, rearing, and grooming in the recorded video ( $5 \mathrm{~min}$; minutes 1 to 6 ) were measured to assess the nicotinewithdrawal signs. ${ }^{14,15,18)}$

Sample Collection and Preparation Following the completion of the final OFT, rats were guillotined under diethyl ether anaesthesia. The brain was promptly removed, and the hippocampus was extracted by dividing the brain along the longitudinal fissure and rapidly freezing it in liquid nitrogen. The frozen hippocampal samples were stored at $-45^{\circ} \mathrm{C}$ until measurement by NMR spectroscopy.

${ }^{1}$ H-NMR Spectroscopy We used a Varian INOVA-700 NMR instrument at $699.7 \mathrm{MHz}$ as the ${ }^{1} \mathrm{H}$ frequency, equipped with a FASTNANO ${ }^{\mathrm{TM}}$ probehead (Agilent Technologies, Santa Clara, CA, U.S.A.). To allow detection, $43 \mu \mathrm{L}$ deuterated water (Sigma-Aldrich Co. LLC, St. Louis, MO, U.S.A.) containing $2.5 \mathrm{~mm}$ sodium-3-(trimethylsilyl)-1-propane-1,1,2,2,3,3- $d_{6}$ sulfonate (DSS- $d_{6}$; Wako Inc., Osaka, Japan) was added to each hippocampal tissue sample (wet weight: $10-20 \mathrm{mg}$ ). The sample was manually homogenized with 20 rotations of a pestle (polypropylene) in a microtube. After the whole volume of the brain homogenate was transferred into a $43-\mu \mathrm{L}$ glass cell with a Pasteur pipette, the cell was set into the 4-mm-outer- diameter zirconium oxide rotor. The rotors were then loaded into the NMR spectrometer.

We measured the NMR spectra under the same conditions as in our previous report. ${ }^{19)}$ The parameters of the NMR spectrometer were set as follows: $90^{\circ}$ pulse width, 7.80-8.00 $\mu \mathrm{s}$ (set for each sample); relaxation delay: $2.000 \mathrm{~s}$; number of data points: $32 \mathrm{k}$ complex; observation width: $8389.3 \mathrm{~Hz}$; number of scans: 128; and rotation speed: $5000 \mathrm{~Hz}$. The pre-saturation sequence was used to eliminate the water signal. The measuring temperature was maintained at $298 \mathrm{~K}$ to narrow the changes in metabolites in the brain tissue caused by the change in temperature during measurement. ${ }^{20)}$ This operation was performed using the VnmrJ software (Ver. 4.0; Agilent Technologies).

Data Analysis of NMR Spectra For multivariate analysis of NMR-derived data, all the acquired free induction decays were zero-filled to $32 \mathrm{k}$ using Alice 2 for the Metabolome software (Ver. 2; JEOL, Tokyo, Japan) and the absolute values were differentiated following Fourier transformation. The chemical shift range of $0.20-10.00 \mathrm{ppm}$ (excluding the range of the water signal: $4.60-4.92 \mathrm{ppm}$ ) in the acquired NMR spectra was integrated in $0.04 \mathrm{ppm}$ buckets to obtain 237 variables. Each bucket was then normalized to give a total integrated area of 100. The obtained integrated values were mean-centred for multivariate analysis. For partial least square discriminant analysis (PLS-DA), ${ }^{21,22)}$ we used the multivariate analysis software SIMCA-P (version 13.0.3, Umetrics, Umea, Sweden).
A

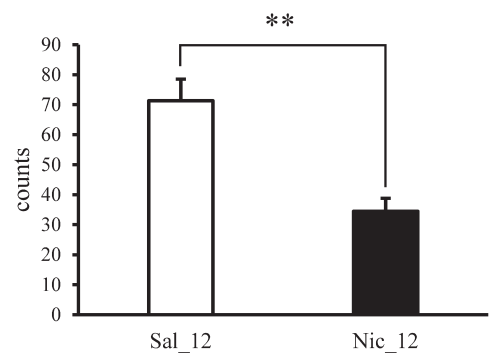

B

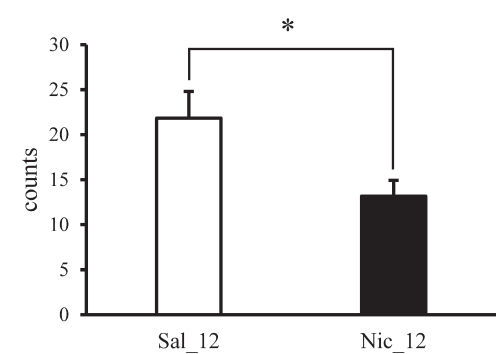

C

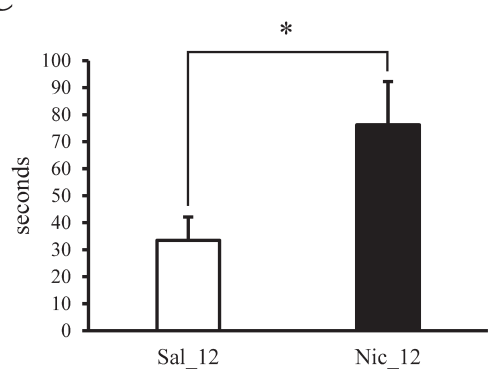

Fig. 1. Results of the Behavioural Pharmacological Testing after the 12-h Nicotine Withdrawal Period

Crossing (number of times a rat crossed a grid line, A), rearing (number of times a rat stood on its hind legs, B), and grooming time (C) $12 \mathrm{~h}$ after nicotine withdrawal. Open columns represent the Sal_12 group $(n=6)$ and closed columns represent the Nic_12 group $(n=6)$. The comparison of the two groups was performed with two-tailed Student's $t$-test. $*: p<0.05, * *: p<0.01$. Mean \pm standard error of the mean (S.E.M.).

A

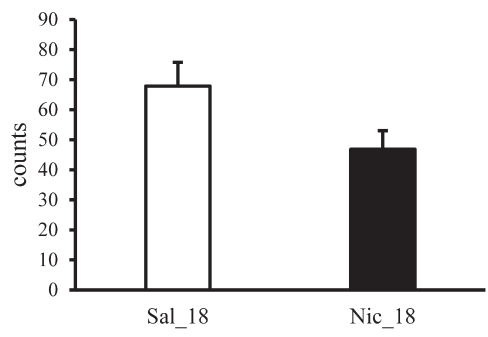

B

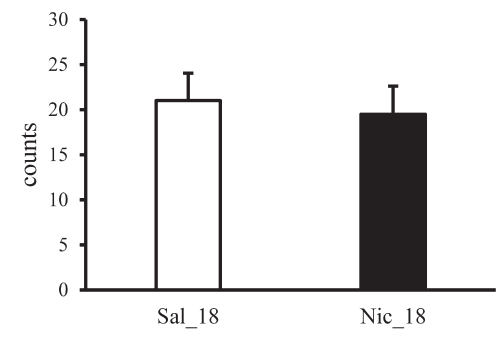

C

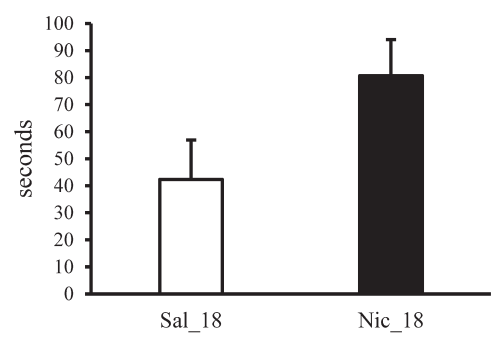

Fig. 2. Results of the Behavioural Pharmacological Testing after the 18-h Nicotine Withdrawal Period

Crossing (number of times a rat crossed a grid line, A), rearing (number of times a rat stood on its hind legs, B), and grooming time (C) $18 \mathrm{~h}$ after nicotine withdrawal. Open columns represent the Sal_18 group $(n=6)$ and closed columns represent the Nic 18 group $(n=6)$. The comparison of the two groups was performed with two-tailed Student's $t$-test. Mean \pm S.E.M. 


\section{RESULTS}

Effect of Withdrawal Period on Behavioural Pharmacological Testing After the 12-h drug withdrawal the Nic_12 group exhibited significantly reduced crossing and rearing behaviours, which are indicators of locomotor activity, compared to the Sal_12 group $(p<0.01, p<0.05$, respectively), while the Nic_12 group had significantly increased grooming time, an indicator of anxiety $(p<0.05)$ (Figs. $1 \mathrm{~A}-\mathrm{C})$. Rats with nicotine-withdrawal symptoms had reduced locomotor activity and increased anxiety, so it was determined that the Nic 12 group was experiencing nicotine-withdrawal symptoms. ${ }^{14,15,18}$

In contrast, in the Nic 18 group, there was no significant change in crossing, rearing, and grooming time (Figs. 2A-C). Based on the results of the OFT, it was determined that the
Nic 18 group had recovered from the nicotine-withdrawal symptoms.

Metabolic Profiling in Rat Experiencing Nicotine-Withdrawal Symptoms The results of PLS-DA for the Nic_12 and Sal_12 groups are shown in Fig. 3. Figure 3A shows the brain metabolic profile of each rat in the Nic_12 and Sal_12 groups, and Fig. 3B is the permutation plot. The brain metabolic profile of the group experiencing nicotine-withdrawal symptoms, could be clearly differentiated from the control group. Because all permuted $R^{2} Y$ (green) and $Q^{2}$ (blue) values on the left were lower than the original point on the right $\left(R^{2} Y\right.$ cum $=0.930, Q^{2}$ cum $=0.735$; Fig. $3 \mathrm{~B}$ ), the permutation plot supported the validity of the PLS-DA model. ${ }^{23)}$

The results of the PLS-DA for the Nic_18 and Sal_18 groups are shown in Fig. 4. Figure 4A shows the brain meta-
A

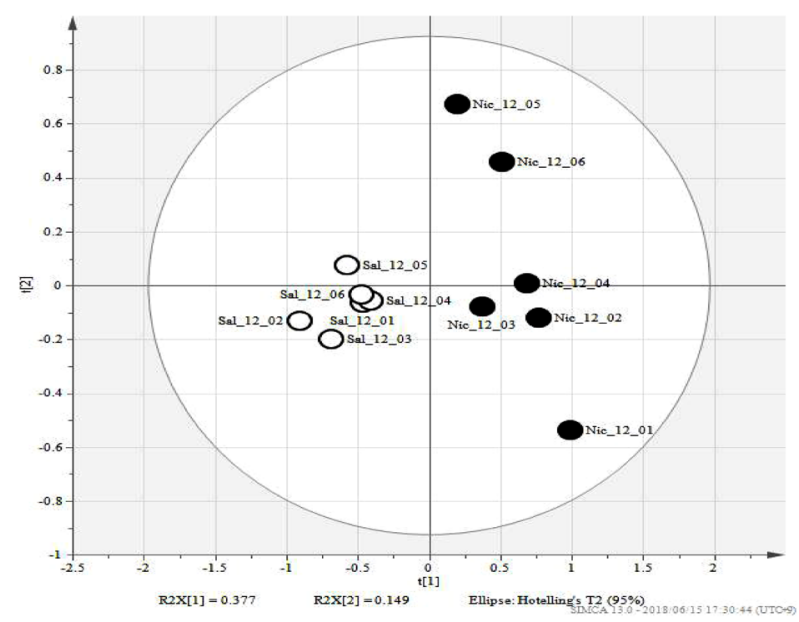

B

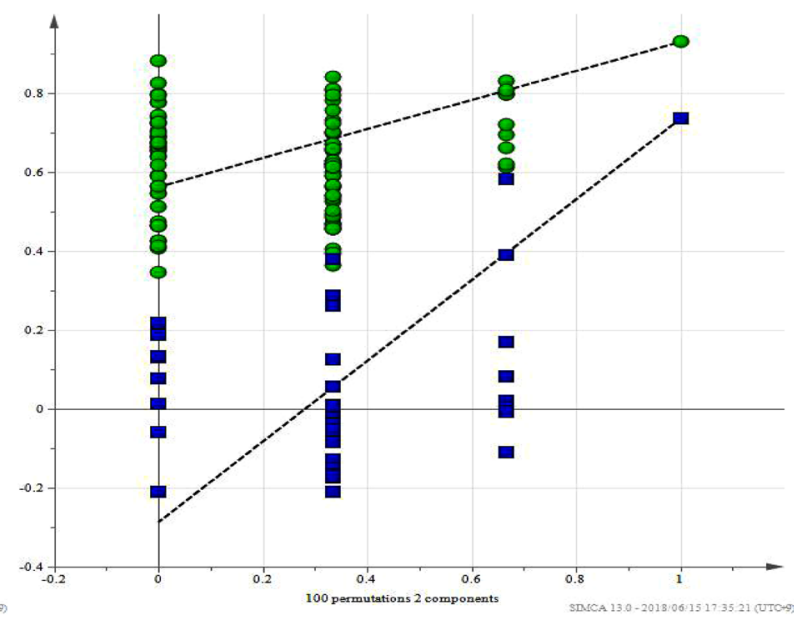

Fig. 3. PLS-DA Score Plot (A) and Statistical Validation (B) of the Nicotine Withdrawal Symptom and Control Groups

The brain metabolic profile (A) for each rat ( $n=6$ /group) and permutation plot (B) obtained by partial least square discriminant analysis (PLS-DA) that were performed to the integral value of each bucket of the hippocampal tissue nuclear magnetic resonance spectra $(0.20-10.00 \mathrm{ppm})$. In the metabolic profile, the nicotine withdrawal symptom group (Nic_12 group) is shown by the closed circles, while the control group (Sal_12 group) is shown by the open circles. $R^{2} Y$ cum $=0.930, Q^{2}$ cum $=0.735\left(R^{2} Y\right.$ ranges from 0 to 1 , while $Q^{2}$ ranges from -1 to 1 ). (Color figure can be accessed in the online version.)

$\mathbf{A}$

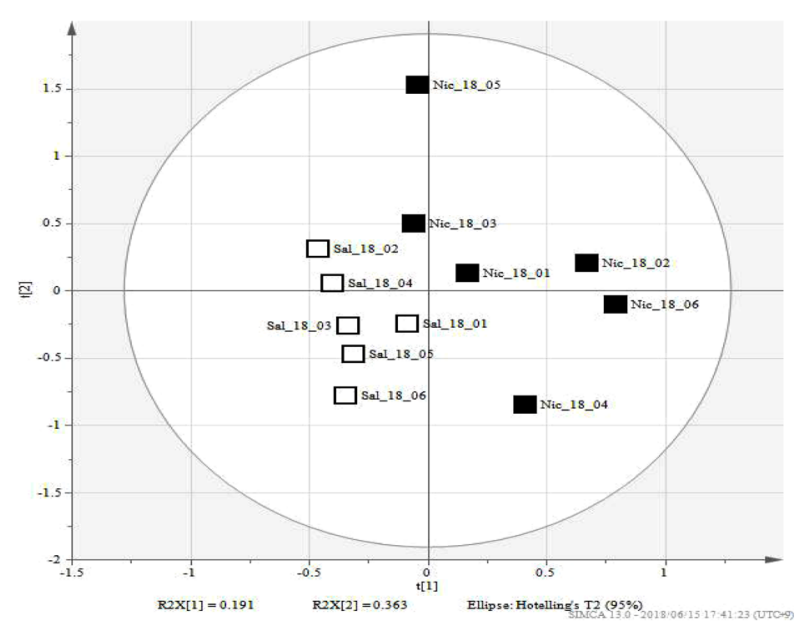

B

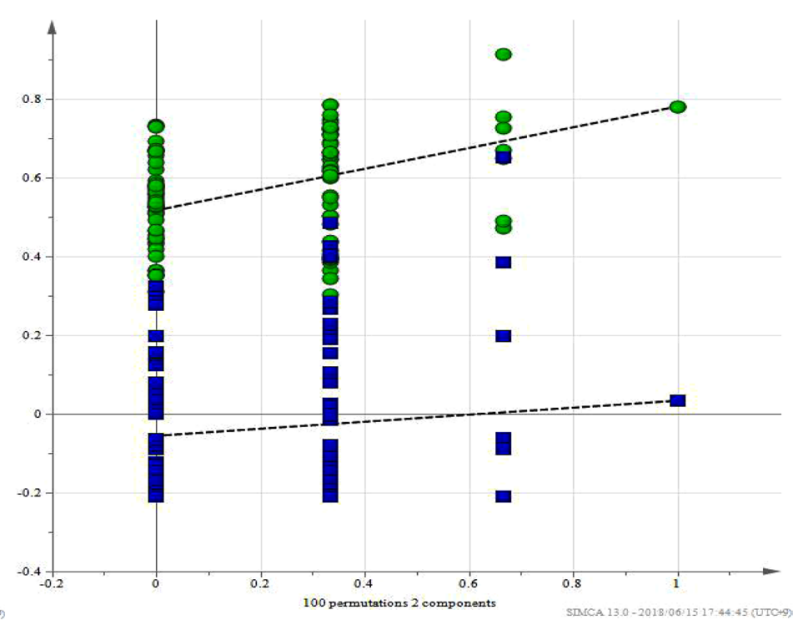

Fig. 4. PLS-DA Score Plot (A) and Statistical Validation (B) of the Group That Recovered from Nicotine Withdrawal Symptoms and the Control Group

The brain metabolic profile (A) for each rat ( $n=6 /$ group) and permutation plot (B) obtained by partial least square discriminant analysis (PLS-DA) that were performed to the integral value of each bucket of the hippocampal tissue nuclear magnetic resonance spectra $(0.20-10.00 \mathrm{ppm})$. In the metabolic profile, the nicotine withdrawa symptom group (Nic 18 group) is shown by the closed squares, while the control group (Sal 18 group) is shown by the open squares. $R^{2} Y$ cum $=0.781, Q^{2}$ cum $=0.033\left(R^{2} Y\right.$ ranges from 0 to 1 , while $Q^{2}$ ranges from -1 to 1 ). (Color figure can be accessed in the online version.) 
Table 1. Changes in Metabolites in the Hippocampus $12 \mathrm{~h}$ after Nicotine Withdrawal

\begin{tabular}{|c|c|c|c|c|c|c|c|}
\hline \multirow{2}{*}{ Metabolite } & \multirow{2}{*}{$\begin{array}{l}\text { Chemical shift }^{a)} \\
(\mathrm{ppm})\end{array}$} & \multirow{2}{*}{$\begin{array}{c}\text { Changed }{ }^{b)} \\
\left(\text { fold difference }^{c)}\right)\end{array}$} & \multirow{2}{*}{$p$ Value } & \multirow{2}{*}{$\begin{array}{l}\text { VIP score } \\
(95 \% \mathrm{CI})\end{array}$} & \multicolumn{3}{|c|}{ Correlation $^{d}$ ) } \\
\hline & & & & & Crossing & Rearing & Grooming \\
\hline Lactate & $\mathbf{1 . 3 2}, 4.10$ & - & 0.31 & $2.00(-1.03$ to 5.04$)$ & -0.02 & 0.07 & -0.10 \\
\hline Alanine & $1.47,3.77$ & - & 0.74 & $0.43(-0.14$ to 1.00$)$ & -0.02 & 0.16 & 0.21 \\
\hline GABA & $1.90,2.29,3.01$ & $\downarrow(0.85)$ & $<0.01$ & $6.55(5.21$ to 7.90$)$ & 0.89 & 0.67 & -0.46 \\
\hline Acetate & 1.91 & - & 0.32 & $0.17(0.02$ to 0.33$)$ & 0.53 & 0.34 & 0.05 \\
\hline$N$-Acetylaspartate & $2.01,2.49,2.68$ & $\uparrow(1.32)$ & $<0.01$ & $8.52(6.71$ to 10.33$)$ & -0.90 & -0.73 & 0.60 \\
\hline Glutamate & $\mathbf{2 . 0 4}, 2.12,2.33$ & $\uparrow(1.09)$ & 0.03 & $0.90(0.24$ to 1.55$)$ & -0.81 & -0.45 & 0.72 \\
\hline Glutamine & $2.14,2.43,3.77$ & - & 0.52 & $0.70(0.08$ to 1.33$)$ & 0.32 & 0.17 & -0.28 \\
\hline Aspartate & $\mathbf{2 . 6 8}, \mathbf{2 . 8 0}, 3.89$ & $\downarrow(0.90)$ & 0.02 & $0.83(0.32$ to 1.34$)$ & 0.56 & 0.69 & -0.42 \\
\hline Choline & $\mathbf{3 . 1 9}, 3.51,4.05$ & - & 0.16 & $1.93(0.41$ to 3.46$)$ & 0.39 & 0.41 & -0.52 \\
\hline Phosphocholine & $\mathbf{3 . 2 1}, 3.58,4.16$ & - & 0.09 & $4.18(1.79$ to 6.58$)$ & 0.45 & 0.41 & -0.54 \\
\hline Myo-inositol & $\mathbf{3 . 2 7}, 3.52,3.61$ & - & 0.23 & $1.98(-0.54$ to 4.49$)$ & -0.06 & -0.19 & 0.22 \\
\hline Creatine & $3.03,3.92$ & $\downarrow(0.89)$ & 0.04 & $3.94(1.83$ to 6.05$)$ & 0.32 & 0.46 & -0.45 \\
\hline
\end{tabular}

a) Bold letters indicate that these peaks were assigned. $b$ ) Arrows represent an increase or decrease of the metabolite compared to the Sal 12 group. $c$ ) Fold differences were calculated by ratios of the mean of the integral value of each bucket and are shown in parentheses. $d$ ) Pearson's correlation between the behavioural score and each metabolite. VIP, variable importance in projection; CI, confidence interval; GABA, $\gamma$-aminobutyrate.

Table 2. Changes in Metabolites in the Hippocampus $18 \mathrm{~h}$ after Nicotine Withdrawal

\begin{tabular}{|c|c|c|c|c|c|c|c|}
\hline \multirow{2}{*}{ Metabolite } & \multirow{2}{*}{$\begin{array}{l}\text { Chemical shift } \\
\text { (ppm) }\end{array}$} & \multirow{2}{*}{$\begin{array}{c}\text { Changed }^{b)} \\
\text { (fold difference }^{c)} \text { ) }\end{array}$} & \multirow{2}{*}{$p$ Value } & \multirow{2}{*}{$\begin{array}{l}\text { VIP score } \\
(95 \% \mathrm{CI})\end{array}$} & \multicolumn{3}{|c|}{ Correlation $^{d)}$} \\
\hline & & & & & Crossing & Rearing & Grooming \\
\hline Lactate & $\mathbf{1 . 3 2}, 4.10$ & - & 0.22 & $5.94(-0.76$ to 12.64$)$ & -0.59 & -0.30 & 0.58 \\
\hline Alanine & $1.47,3.77$ & - & 0.50 & $1.19(-1.65$ to 4.04$)$ & 0.04 & -0.23 & 0.40 \\
\hline GABA & $1.90,2.29,3.01$ & - & 0.32 & $3.02(-2.48$ to 8.52$)$ & -0.05 & 0.02 & 0.24 \\
\hline Acetate & 1.91 & - & 0.57 & $0.17(-0.02$ to 0.36$)$ & 0.16 & 0.09 & 0.08 \\
\hline$N$-Acetylaspartate & $2.01,2.49,2.68$ & - & 0.44 & $2.94(-1.09$ to 6.97$)$ & 0.00 & -0.07 & -0.19 \\
\hline Glutamate & $\mathbf{2 . 0 4}, 2.12,2.33$ & - & 0.42 & $0.71(-0.88$ to 2.29$)$ & -0.12 & -0.06 & -0.10 \\
\hline Glutamine & $2.14, \mathbf{2 . 4 3}, 3.77$ & - & 0.52 & $0.60(0.08$ to 1.13$)$ & -0.02 & 0.27 & -0.09 \\
\hline Aspartate & $\mathbf{2 . 6 8}, \mathbf{2 . 8 0}, 3.89$ & - & 0.77 & $0.18(-0.37$ to 0.73$)$ & 0.12 & 0.28 & 0.39 \\
\hline Choline & $\mathbf{3 . 1 9}, 3.51,4.05$ & - & 0.05 & $5.71(0.11$ to 11.32$)$ & 0.39 & 0.19 & -0.58 \\
\hline Phosphocholine & $\mathbf{3 . 2 1}, 3.58,4.16$ & - & 0.67 & $1.94(-1.25$ to 5.14$)$ & -0.06 & -0.16 & -0.18 \\
\hline Myo-inositol & $3.27,3.52,3.61$ & - & 0.33 & $3.50(0.36$ to 6.63$)$ & 0.56 & 0.16 & -0.26 \\
\hline Creatine & $3.03, \mathbf{3 . 9 2}$ & - & 0.99 & $3.85(0.50$ to 7.20$)$ & 0.12 & 0.11 & 0.15 \\
\hline
\end{tabular}

a) Bold letters indicate that these peaks were assigned. b) An increase or decrease of the metabolite compared to the Sal_18 group. $c$ ) Fold differences were calculated by ratios of the mean of the integral value of each bucket and are shown in parentheses. $d$ ) Pearson's correlation between behavioural score and each metabolite. VIP, variable importance in projection; CI, confidence interval; GABA, $\gamma$-aminobutyrate.

bolic profile of each rat in the Nic_18 and Sal_18 groups, and Fig. 4B is the permutation plot. The brain metabolic profile of the group that recovered from nicotine-withdrawal symptoms could be clearly differentiated from the control group. However, some of the permuted $R^{2} Y$ and $Q^{2}$ values were higher than the original points $\left(R^{2} Y\right.$ cum $=0.781, Q^{2}$ cum $=0.033$; Fig. 4B). Therefore, the permutation plot did not support the validity of the PLS-DA model.

Changes in Metabolites in the Hippocampi of Rats Experiencing Nicotine-Withdrawal Symptoms Table 1 shows the change in metabolites in the brain during the 12-h nicotine-withdrawal periods obtained through relative comparison of the integral value of each bucket in the NMR spectra. Potential metabolic biomarkers were selected when the $95 \%$ confidence interval (CI) lower limit of variable importance in projection (VIP) score was $>1.0$ and the $p$-value calculated from the Student's $t$-test was $<0.05{ }^{24)}$ The Nic_12 group had significant elevation of $\mathrm{N}$-acetylaspartate and glutamate and had significant reduction in aspartate, $\gamma$-aminobutyric acid (GABA), glutamine, and creatine compared to the Sal_12 group. Additionally, the 95\% CI lower limit of the VIP score for three types of metabolites: $N$-acetylaspartate, GABA, and creatine was higher than 1.0. Therefore, these metabolites were identified as potential biomarker candidates in the Nic_12 group. In addition, among the potential biomarker candidates, GABA and $N$-acetylaspartate showed a strong correlation $(|r|>0.70)$ with the results of our behavioural pharmacological evaluation, but no strong correlation was observed for creatine. Table 2 describes the changes in metabolite levels in the brain during the 18 -h nicotine withdrawal period. We were unable to confirm that the level of any metabolites in the hippocampus significantly changed in the Nic_18 group, which had recovered from nicotine withdrawal symptoms compared to the Sal_18 group. Additionally, no metabolites strongly correlated with the results of our behavioural pharmacological evaluation $18 \mathrm{~h}$ after withdrawal.

\section{DISCUSSION}

We aimed to investigate whether the results of the me- 
tabolomic analysis of the rat brain reflect nicotine-withdrawal symptoms. We also aimed to investigate the relative changes in each metabolite in the brains of rats with nicotine-withdrawal symptoms. The brain metabolic profile of rats experiencing nicotine-withdrawal symptoms clearly differed from that of control rats. Three types of metabolites: $N$-acetylaspartate, GABA, and creatine significantly contributed to the differentiation. Furthermore, among these three metabolites, $N$-acetylaspartate and GABA showed a strong correlation with the results of our behavioural pharmacological evaluation. This suggests that $N$-acetylaspartate and GABA levels may reflect behavioural changes in nicotine withdrawal symptoms. The brain metabolic profile of rats having recovered from nicotine-withdrawal symptoms clearly differed from that of control rats. However, the statistical validity of the PLS-DA model was poor and potential biomarker candidates were not detected.

$\mathrm{N}$-acetylaspartate is present in neurons at a high density, ${ }^{25)}$ and it is formed from aspartate and acetyl-CoA by aspartate $\mathrm{N}$-acetyltransferase. ${ }^{26)} \mathrm{N}$-acetylaspartate is also known as a neuronal density marker, so the increase of $N$-acetylaspartate levels in the brain tissue reflects elevated neuronal density. ${ }^{27,28)}$ In this study, because aspartate decreased and $N$-acetylaspartate increased significantly, it is suggested that aspartate $\mathrm{N}$ acetyltransferase activity could be high.

GABA is formed from glutamate by glutamate decarboxylase (GAD). It is reported that GABAergic neurons are associated with neurogenesis and neuronal differentiation in the hippocampus. ${ }^{29,30)}$ As a result of this study, because glutamate increased and GABA decreased significantly, it is suggested that GAD activity could have decreased and neurogenesis and neuronal differentiation could have changed.

Creatine is biosynthesised by L-arginine: glycine amidinotransferase (AGAT) and $N$-guanidinoacetate methyltransferase (GAMT) in peripheral tissues and is transported into brain tissues by a transporter called SLC6A8 via microcapillary endothelial cells (MCEC). ${ }^{31,32)}$ It is already known that creatine is involved in energy storage $\mathrm{e}^{33)}$ and has shown neuroprotective properties. ${ }^{34)}$ Reduction of creatine in the brain is also known to cause deficits in GABAergic synapses. ${ }^{35,36)}$ Therefore, the decrease in creatine reflects abnormal energy metabolism in the hippocampus. However, as there have been no reports stating that the level of expression or activity of AGAT, GAMT, or SLC6A8 changes in the nicotine withdrawal symptom state, why creatine levels in hippocampal tissue decrease during this state remains unclear.

According to the results of the present study, creatine reduction was observed in the nicotine-withdrawal state hippocampus, supporting the reduction of GABA during the nicotine withdrawal symptoms. $N$-Acetylaspartate is also known to be a neuronal density marker in addition to having an inducing effect on neuronal differentiation. ${ }^{37)}$ Therefore, in the nicotine-withdrawal state hippocampus, reduction of GABAergic neurons decreased neurogenesis and neuronal differentiation, and there is a possibility that $\mathrm{N}$-acetylaspartate may have increased to improve this decreased neuronal differentiation.

Conflict of Interest The authors declare no conflict of interest.

\section{REFERENCES}

1) Anthenelli RM, Benowitz NL, West R, St Aubin L, McRae T, Lawrence D, Ascher J, Russ C, Krishen A, Evins AE. Neuropsychiatric safety and efficacy of varenicline, bupropion, and nicotine patch in smokers with and without psychiatric disorders (EAGLES): a double-blind, randomized, placebo-controlled clinical trial. Lancet, 387, 2507-2520 (2016).

2) Aubin HJ, Bobak A, Britton JR, Oncken C, Billing CB Jr, Gong J, Williams KE, Reeves KR. Varenicline versus transdermal nicotine patch for smoking cessation: results from a randomized open-label trial. Thorax, 63, 717-724 (2008).

3) U.S. Food and Drug Administration. "Varenicline (marketed as Chantix) Information.”: 〈https://www.fda.gov/Drugs/DrugSafety/PostmarketDrugSafetyInformationforPatientsandProviders/ ucm106540.htm>, cited 22 June, 2017.

4) Akimoto $H$, Oshima $S$, Negishi A, Ohara $K$, Ohshima $S$, Inoue N, Kobayashi D. Assessment of the risk of suicide-related events induced by concomitant use of antidepressants in cases of smoking cessation treatment with varenicline and assessment of latent risk by the use of varenicline. PLOS ONE, 11, e0163583 (2016).

5) Shiffman S, West R, Gilbert D; SRNT Work Group on the Assessment of Craving and Withdrawal in Clinical Trials. Recommendation for the assessment of tobacco craving and withdrawal in smoking cessation trials. Nicotine Tob. Res., 6, 599-614 (2004).

6) Pfizer, "CHANTIX ${ }^{\mathbb{R}}$ (VARENICLINE).”: 〈http://www.pfizer.com/ products/product-detail/chantix), cited 23 June, 2017.

7) Kenny PJ, Markou A. Neurobiology of the nicotine withdrawal syndrome. Pharmacol. Biochem. Behav., 70, 531-549 (2001).

8) Zhang Y, Liu W, Zhou Y, Ma C, Li S, Cong B. Endoplasmic reticulum stress is involved in restraint stress-induced hippocampal apoptosis and cognitive impairments in rats. Physiol. Behav., 131, 41-48 (2014).

9) Lucassen PJ, Heine VM, Muller MB, van der Beek EM, Wiegant VM, De Kloet ER, Joels M, Fuchs E, Swaab DF, Czeh B. Stress, depression and hippocampal apoptosis. CNS Neurol. Disord. Drug Targets, 5, 531-546 (2006).

10) Videbech P, Ravnkilde B, Pedersen TH, Hartvig H, Egander A, Clemmensen K, Rasmussen NA, Andersen F, Gjedde A, Rosenberg R. The Danish PET/depression project: clinical symptoms and cerebral blood flow. A regions-of-interest analysis. Acta Psychiatr. Scand., 106, 35-44 (2002).

11) Merritt PS, Cobb AR, Moissinac L, Hirshman E. Evidence that episodic memory impairment during tobacco abstinence is independent of attentional mechanisms. J. Gen. Psychol., 137, 331-342 (2010).

12) Mendrek A, Monterosso J, Simon SL, Jarvik M, Brody A, Olmstead R, Domier CP, Cohen MS, Ernst M, London ED. Working memory in cigarette smokers: comparison to non-smokers and effects of abstinence. Addict. Behav., 31, 833-844 (2006).

13) Jacobsen LK, Krystal JH, Mencl WE, Westerveld M, Frost SJ, Pugh KR. Effects of smoking and smoking abstinence on cognition in adolescent tobacco smokers. Biol. Psychiatry, 57, 56-66 (2005).

14) Mannucci C, Navarra M, Calzavara E, Caputi AP, Calapai G. Serotonin involvement in rhodiola rosea attenuation of nicotine withdrawal signs in rats. Phytomedicine, 19, 1117-1124 (2012).

15) Motaghinejad M, Fatima S, Karimian M, Ganji S. Protective effects of forced exercise against nicotine-induced anxiety, depression and cognition impairment in rat. J. Basic Clin. Physiol. Pharmacol., 27, 19-27 (2016).

16) Epping-Jordan MP, Watkins SS, Koob GF, Markou A. Dramatic decreases in brain reward function during nicotine withdrawal. $\mathrm{Na}$ ture, 393, 76-79 (1998).

17) Zhu X, Xia O, Han W, Shao M, Jing L, Fan Q, Liu Y, Diao J, Lv Z, Sun X. Xiao yao san improves depressive-like behavior in rats through modulation of $\beta$-arrestin 2-mediated pathways in hippocampus. Evid. Based Complement. Alternat. Med., 2014, 902516 
(2014).

18) Kotagale NR, Chopde CT, Umekar MJ, Taksande BG. Chronic agmatine treatment prevents behavioral manifestations of nicotine withdrawal in mice. Eur. J. Pharmacol., 754, 190-198 (2015).

19) Akimoto H, Oshima S, Ohara K, Negishi A, Hiroyama H, Nemoto T, Kobayashi D. High-resolution magic-angle spinning-'H-NMR spectroscopy-based metabolic profiling of hippocampal tissue in rats with depression-like symptoms. Biol. Pharm. Bull., 40, 789-796 (2017)

20) Tomita $S$, Nemoto $T$, Matsuo $Y$, Shoji $T$, Tanaka F, Nakagawa H, Ono H, Kikuchi J, Ohnishi-Kameyama M, Sekiyama Y. A NMR-based, non-targeted multistep metabolic profiling revealed L-rhamnitol as a metabolite that characterised apples from different geographic origins. Food Chem., 174, 163-172 (2015).

21) Brereton RG, Lloyd GR. Partial least squares discriminant analysis: taking the magic away. J. Chemometr., 28, 213-225 (2014).

22) Gromski PS, Muhamadali H, Ellis DI, Xu Y, Correa E, Turner ML, Goodacre R. A tutorial review: Metabolomics and partial least squares-discriminant analysis - a marriage of convenience or a shotgun wedding. Anal. Chim. Acta, 879, 10-23 (2015).

23) Ke C, Li A, Hou Y, Sun M, Yang K, Cheng J, Wang J, Ge T, Zhang F, Li Q, Li J, Wu Y, Lou G, Li K. Metabolic phenotyping for monitoring ovarian cancer patients. Sci. Rep., 6, 23334 (2016)

24) Sun M, Gao X, Zhang D, Ke C, Hou Y, Fan L, Zhang R, Liu H, Li $\mathrm{K}, \mathrm{Yu} \mathrm{B}$. Identification of biomarkers for unstable angina by plasma metabolomic profiling. Mol. Biosyst., 9, 3059-3067 (2013).

25) Urenjak J, Williams SR, Gadian DG, Noble M. Specific expression of $\mathrm{N}$-acetylaspartate in neurons, oligodendrocyte-type-2 astrocyte progenitors, and immature oligodendrocytes in vitro. J. Neurochem., 59, 55-61 (1992).

26) Wiame E, Tyteca D, Pierrot N, Collard F, Amyere M, Noel G, Desmedt J, Nassogne MC, Vikkula M, Octave JN, Vincent MF, Courtoy PJ, Boltshauser E, van Schaftingen E. Molecular identification of aspartate $N$-acetyltransferase and its mutation in hypoacetylaspartia. Biochem. J., 425, 127-139 (2009).

27) Moffett JR, Ross B, Arun P, Madhavarao CN, Namboodiri AM. $N$ Acetylaspartate in the CNS: from neurodiagnostics to neurobiology. Prog. Neurobiol., 81, 89-131 (2007)

28) Nakano M, Ueda H, Li JY, Matsumoto M, Yanagihara T. Measurement of regional $n$-acetylaspartate after transient global ischemia in gerbils with and without ischemic tolerance: an index of neuronal survival. Ann. Neurol., 44, 334-340 (1998).

29) Tozuka Y, Fukuda S, Namba T, Seki T, Hisatsune T. GABAergic excitation promotes neuronal differentiation in adult hippocampal progenitor cells. Neuron, 47, 803-815 (2005).

30) Sibbe M, Kulik A. GABAergic regulation of adult hippocampal neurogenesis. Mol. Neurobiol., 54, 5497-5510 (2017).

31) Braissant O. Creatine and guanidinoacetate transport at blood-brain and blood-cerebrospinal fluid barriers. J. Inherit. Metab. Dis., 35, 655-664 (2012)

32) Joncquel-Chevalier Curt M, Voicu PM, Fontaine M, Dessein AF, Porchet N, Mention-Mulliez K, Dobbelaere D, Soto-Ares G, Cheillan D, Vamecq J. Creatine biosynthesis and transport in health and disease. Biochimie, 119, 146-165 (2015).

33) Wallimann T, Wyss M, Brdiczka D, Nicolay K, Eppenberger HM. Intracellular compartmentation, structure and function of creatine kinase isoenzymes in tissues with high and fluctuating energy demands: the 'phosphocreatine circuit' for cellular energy homeostasis. Biochem. J., 281, 21-40 (1992).

34) Cunha MP, Martín-de-Saavedra MD, Romero A, Egea J, Ludka FK, Tasca CI, Farina M, Rodrigues AL, López MG. Both creatine and its product phosphocreatine reduce oxidative stress and afford neuroprotection in an in vitro Parkinson's model. ASN Neuro., 6, pii: 1759091414554945 (2014)

35) Baroncelli L, Molinaro A, Cacciante F, Alessandrì MG, Napoli D, Putignano E, Tola J, Leuzzi V, Cioni G, Pizzorusso T. A mouse model for creatine transporter deficiency reveals early onset cognitive impairment and neuropathology associated with brain aging. Hum. Mol. Genet., 25, 4186-4200 (2016).

36) Pazini FL, Cunha MP, Azevedo D, Rosa JM, Colla A, de Oliveira J, Ramos-Hryb AB, Brocardo PS, Gil-Mohapel J, Rodrigues ALS. Creatine prevents corticosterone-induced reduction in hippocampal proliferation and differentiation: possible implication for its antidepressant effect. Mol. Neurobiol., 54, 6245-6260 (2017).

37) Mazzoccoli $C$, Ruggieri $V$, Tataranni $T$, Agriesti $F$, Laurenzana I, Fratello A, Capitanio N, Piccoli C. N-acetylaspartate (NAA) induces neuronal differentiation of SH-SY5Y neuroblastoma cell line and sensitizes it to chemotherapeutic agents. Oncotarget, 7 , 26235-26246 (2016). 